\title{
Editorial overview: theoretical traditions in social values for sustainability
}

\author{
Christopher M. Raymond ${ }^{1,2,3} \cdot$ Jasper O. Kenter $^{4} \cdot$ Carena J. van Riper ${ }^{5} \cdot$ Andrea Rawluk $^{6} \cdot$ Dave Kendal $^{7}$
}

Received: 11 June 2019 / Accepted: 5 August 2019 / Published online: 22 August 2019

(c) Springer Japan KK, part of Springer Nature 2019

\begin{abstract}
This special feature provides an impression of the plurality of social values for sustainability, taking into account theoretical traditions within mainstream and heterodox economics; positive, social and environmental psychology; human geography; anthropology; sociology; religious and indigenous studies and business management. Papers in this issue respond to questions of: how do we conceptualise social values; how do we integrate or share social values; what are processes for learning about and mechanisms for forming and changing social values; and what are the associations between social values and behaviour or well-being? Consistent with post-normal science, we suggest that there is no one correct way of conceptualising, assessing, integrating or activating social values for sustainability. We present five arguments: (1) the plurality of social values can be conceptualised along many different dimensions, with reference to value, epistemic and procedural lenses; (2) values are nested in different hierarchies, resulting in the potential for different forms of value articulations and pathways of value expression; (3) not all social values are pre-formed and readily drawn upon, instead needing pathways of deliberation or intervention to be activated; (4) social values may change through different processes or pathways of intervention, and; (5) power matters in the formation and assessment of social values. We discuss the tensions that arise when attempting to integrate different perspectives and introduce the notion of 'navigation' to begin to address these tensions. Navigation requires scholars to adopt a more critical and reflexive approach to value enquiry than is currently espoused in sustainability science and practice.
\end{abstract}

Keywords Social values $\cdot$ Integrated valuation $\cdot$ Ecosystem services $\cdot$ Non-monetary valuation $\cdot$ Environment $\cdot$ Deliberation

Handled by Osamu Saito, United Nations University Institute for the Advanced Study of Sustainability, Japan.

Christopher M. Raymond

christopher.raymond@helsinki.fi

1 Helsinki Institute for Sustainability Science (HELSUS), University of Helsinki, Yliopistonkatu 3, 00014 Helsinki, Finland

2 Ecosystems and Environment Research Program, Faculty of Biological and Environmental Sciences, University of Helsinki, Viikinkaari 1, 00014 Helsinki, Finland

3 Department of Economics and Management, Faculty of Agriculture and Forestry Sciences, University of Helsinki, Latokartanonkaari 7, 00014 Helsinki, Finland

\section{Introduction}

It is now widely acknowledged that social legitimacy of transformations toward sustainability demands forms of governance that take into account a plurality of values and systems of knowledge (Díaz et al. 2019). The Intergovernmental

4 Department of Environment and Geography, University of York, Wentworth Way, Heslington, York YO10 5NG, UK

5 Department of Natural Resources and Environnmental Sciences, University of Illinois at Urbana-Champagne, W-503 Turner Hall, 1102 South Goodwin Ave, Urbana, IL 61801, USA

6 School of Ecosystem and Forest Sciences, University of Melbourne, Baldwin Spencer Building (113), Parkville, VIC 3010, Australia

7 Geography and Spatial Sciences, University of Tasmania, Private Bag 78, Hobart, TAS 7001, Australia 
Science-Policy Platform on Biodiversity and Ecosystem Services (IPBES) has adopted a 'nature's contribution to people' framing of human-environment relationships to actively engage and respect local, indigenous and western scientific knowledge and their associated value systems in biodiversity assessments (Pascual et al. 2017; Díaz et al. 2018; IPBES 2019). The European Commission has shifted from green infrastructure and ecosystem-based assessments to naturebased solutions and co-benefit assessments (European Commission 2015) in order to take into account the multiple ways that individuals and groups value nature and to mitigate the impacts from climate change, conserve biodiversity and improve human health and well-being (Cohen-Shacham et al. 2016; Raymond et al. 2017). The Intergovernmental Panel on Climate Change (IPCC) also seeks to include multiple knowledge systems and values into its assessments, though there are also critiques of the degree to which this is achieved (Ford et al. 2016). These frameworks align with scholarly discussions about the importance of recognising multiple values in environmental assessments, beyond instrumental ones (de Groot et al. 2002; Kenter et al. 2016a; Muraca 2016; Arias-Arévalo et al. 2018; Himes and Muraca 2018; Chan et al. 2018).

Social values constitute a fuzzy boundary concept that relates to a variety of values that may, amongst other characteristics, be shared, transcendental, other-regarding, communal, cultural, group-based, deliberated or pertaining to values to or about society (Kenter et al. 2015). In search of values plurality, we, and others, have dedicated efforts toward clarifying the theoretical, conceptual and methodological basis of social values. We have presented conceptual frameworks that clarify social values across value dimensions and lenses (Kenter et al. 2015, 2019) and a special issue building on the UK National Ecosystem Assessment investigated the interrelations between social, shared, cultural and plural values (Kenter 2016a). We have developed empirical techniques for assessing the multiple levels or facets of value (van Riper et al. 2018; Rawluk et al. 2018b), critiqued the multiple assumptions that underpin different ways of aggregating social values for sustainability (Raymond et al. 2014), and assessed the multiple pathways between these values and attitudes, beliefs and behaviours relevant to ecological management and conservation (Raymond et al. 2011; Ives and Kendal 2014; Raymond and Kenter 2016). We have also considered methods for enhancing management of ecosystem services based on social values collated using participatory mapping (Raymond et al. 2009; Bryan et al. 2010; Kenter 2016b), shaped through deliberative valuation techniques (Kenter et al. 2011, 2016c; Orchard-Webb et al. 2016), and understood as emergent from social learning experiments (Eriksson et al. 2019).

These efforts have complemented scholarly debates concerning how to recognise the importance of different kinds of values in decision-making (for an overview, see: AriasArévalo et al. 2017). The division of instrumental benefits of the environment into use and non-use (or passive-use) values is well-established (Arrow et al. 1993; Carson et al. 2001; Tinch et al. 2019). In parallel, philosophical arguments have been made about the structure of the worth of nature in- and for itself, building on the long tradition of studying intrinsic values in environmental ethics (Rolston 1988; Callicott 1992; O'Neill 1992; Muraca 2011; Davidson 2013; Batavia and Nelson 2017; Piccolo 2017; O'Connor and Kenter 2019). Most recently, there has been a renaissance of attention to relational values, defined by Chan et al. (2016) as preferences, principles and virtues about humannature relationships. A special issue clarified what relational values are (and are not) in terms of concepts, components, disciplinary roots, and applications (Chan et al. 2018).

Concurrently, substantial attention has been devoted to the development of integrated valuation techniques, which can help put assessment of social values on a par with conventional economic valuation and biophysical assessment. Integrated valuation seeks to include a plurality of values in decision-making by combining diverse approaches and methods, and different knowledge systems (Gómez-Baggethun et al. 2014; Scholte et al. 2015; Jacobs et al. 2016, 2018). Jacobs et al. (2016) suggested that different valuation methods could elicit diverse value types, with each method having its blind spots. To manage this complexity, decision trees have been developed for guiding the selection of valuation methods in environmental decision-making (Harrison et al. 2018).

However, we are concerned that many insights from established theoretical traditions within the social sciences and humanities, such as within the disciplines of positive, social and environmental psychology, sociology and religious studies, remain peripheral in current discussions on social values for sustainability. This view extends from recent arguments that IPBES still inclines towards a realist, instrumental perspective on nature (Kenter 2018) that creates idealizations for managing complexity but does not translate back into concrete policies (Evans 2019). We also call attention to the neglect in ecosystem assessments of transcendental values and cultural phenomena and identities that provide deeper leverage points for bringing about transformational change. The ecosystem services literature focuses almost exclusively on values of nature, largely omitting consideration of our deeper held values in relation to it (Schwartz 1994; Teel et al. 2007; Raymond and Kenter 2016; Dietsch et al. 2019). Additionally, given a tendency for much previous research to assume that values are pre-formed and can be sufficiently captured using static, cross-sectional data (Poteete et al. 2010), we argue that definitions of social values should be pluralistic to accommodate multiple lenses and expressions of value through individual, group and societal processes of value formation and change 
(Irvine et al. 2016; van Riper et al. 2017; Kendal and Raymond 2018; Kenter et al. 2019).

In this special feature, we propose a widening of the theoretical basis for social values enquiry considered in sustainability science and practice, in recognition that interdisciplinary frameworks are often not fully grounded in the long history and broader context of social values theory development and application across multiple disciplines (Raymond et al. 2018). We present social values from diverse theoretical traditions such as mainstream and heterodox economics (Ravenscroft 2019; Massenberg 2019), social and environmental psychology (van Riper et al. 2019), religion and faith studies (Christie et al. 2019a; Ives and Kidwell 2019), transformation-oriented sustainability science (Horcea-Milcu et al. 2019), corporate social responsibility and business management (Fordham and Robinson 2019), indigenous philosophy (Gould et al. 2019), sociology (Brear and Mbonane 2019) and positive psychology (Raymond and Raymond 2019). Other papers synthesise knowledge across traditions to better understand the multiple dimensions of values and valuing (Rawluk et al. 2018a), the temporal dynamics of values (Kendal and Raymond 2018), the inter-relations between social, relational, intrinsic and other key values concepts in ecosystem assessment (O'Connor and Kenter 2019; Stålhammar and Thorén 2019), the co-construction of values (Calcagni et al. 2019) and the integration of values to inform environmental policy and decision-making (Christie et al. 2019b; Kronenberg and Andersson 2019).

We make five major arguments in this special feature:

(1) Social values differ across complex and manifold dimensions, and with reference to value, epistemic and procedural lenses. Before attempting to integrate values, one needs to navigate their plurality by paying attention to the context of valuation and one's knowledge perspective.

(2) Values are nested in different hierarchies, resulting in the potential for different forms of value articulations with complex relationships that vary across space and time.

(3) Many values are not pre-formed, and require pathways of deliberation and/or intervention to be formed or activated.

(4) Social values may change through different processes or pathways of intervention.

(5) Power matters in the formation and assessment of social values.

\section{Organisation of the special feature}

The special feature is organized under four broad questions: (1) How do we conceptualise social values? (2) How do we integrate or establish shared social values? (3) What are processes for learning about, forming or changing social values? (4) What are the associations between social values and behaviour or well-being? (see Fig. 1). In the first question, we consider the different ways in which social values can be conceptualised, taking into account different theoretical traditions and nuances in the way values have been identified or assessed within disciplines such as economics. In the second question, we explore possibilities for integrating the multiple forms of social values using integrative frameworks (the Life Framework), different methods of value aggregation, or different communicative and deliberative processes for achieving shared social values. In the third question, we consider how value articulating institutions, including religious institutions or teachings, enculturate particular types of social values yet can impede others. We also consider different mechanisms of value change, including change within the individual, group processes and socio-ecological context. As an example of learning through group processes, we illustrated how definitions of social value were refined by the special feature writing team through deliberations at a two-day workshop (Eriksson et al. 2019). In the fourth question, we consider the multiple pathways or levels of association between social values and behaviour, or values and well-being.

\section{How do we conceptualise social values?}

The papers included in this Special Feature address different concepts of value. Some papers explore concepts across both disciplines and theoretical traditions. (Rawluk et al. 2018a), for example, explore the underlying ontological positioning of values. They identify tensions between the level of abstractness of values (locatable, tangible objects or places vs. abstract ideas or principles) and contextualisation of values (stable and generalizable vs. continually and situationally constructed). A framework is provided for mapping value concepts across different levels of abstractness and context dependency.

Stålhammar and Thorén (2019) critically discuss how recent concepts of relational values fit into the three fields of environmental ethics, ecosystem service valuation and environmental psychology, and how relational values align with different types of social values. They critique the conception of relational values as a non-instrumental anthropocentric ethical category, yet point out the potential of relational values as a boundary object that can serve to broaden the epistemic lenses through which values of nature are regarded. Drawing on this spectrum, they make the case that relational values could be conceived as an approach rather than a concept.

Other papers draw upon particular perspectives. Gould et al. (2019) present a suite of values seen as core to Hawaiian ways of knowing, and discuss how Hawaiian 


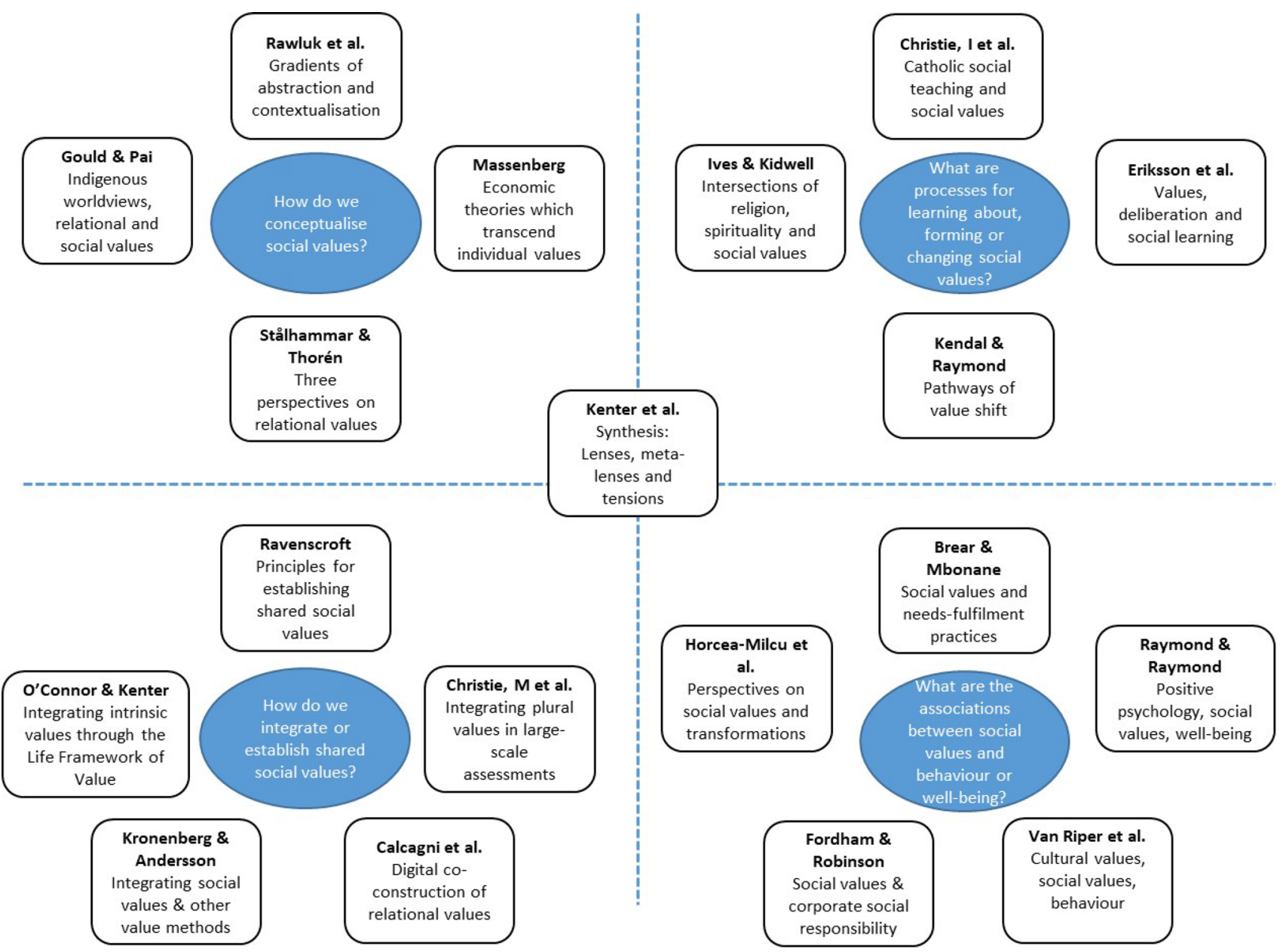

Fig. 1 Four questions which guide the organisation of the special feature

perceptions of values inform and enrich the concepts of relational values and social values. These authors highlight the importance of eliciting and integrating indigenous perspectives into social and relational value assessments. They consider cross-fertilisation between indigenous, relational and social value perspectives, where the 'common good' as conceived of in social values literature may be more inclusive of non-humans and understandings of reciprocity, while the evolution of relational values may draw on both the participatory approaches emphasised by social values scholars as well as indigenous practices for recognising lived values.

Massenberg (2019) reviews theories throughout the history of economics that challenge or transcend the individualistic, instrumental assumptions of neoclassical economic thought. He argues that economic theory is not as narrowly focussed on individual values and self-interest, as is commonly claimed, and that recent social values scholars within sustainability science could draw upon a broad range of historical insights and arguments within the mainstream tradition to strengthen their case for social and deliberative valuation and enrich its theoretical foundations.

\section{How do we integrate or establish shared social values?}

Scholars can accommodate diverse voices and plural values by recognising multiple metaphors of human nature relationships (Raymond et al. 2013). However, plural valuation often involves seeking some level of value integration (Klain et al. 2014), and shared social values in the sense of a common good can reflect different values across multiple value lenses and dimensions (Kenter et al. 2019). As a means to both communicate and integrate different perspectives on value and link values to multiple frames of people-nature relations, O'Connor and Kenter (2019) present the Life Framework of Values. Building on the work of O'Neill et al. (2008), these authors conceive of values that emerge from living with, from, in, and as the world. An important promise of the framework is that it can integrate the instrumental and 
relational values associated with ecosystem services and nature's contributions to people with intrinsic values of the more-than-human world within a single cohesive understanding. The relevance of the Life Framework is demonstrated by conceptually and empirically exploring articulated intrinsic values, defined as ends without reference to humans as valuing agents that nonetheless can be articulated by people, in relation to the different Life Frames.

Several papers in this special feature investigate whether integration of plural values is possible, and if so, how. Based on the IPBES European and Central Asia assessment, Christie et al. (2019b) present a pragmatic approach for assessing diverse values and worldviews in relation to nature's contributions to people (NCP). Their analysis demonstrates that the IPBES approach combining economic and socio-cultural valuation methods and working with indigenous and local knowledge holders provided for a greater plurality of values than previous large-scale ecosystem assessments. They conclude that to address more fully the plurality of values, future IPBES assessments would need to more explicitly consider gradients in terms of: the type of representation sought, the scale of the provider from the individual to that of a culture or community, the scale of application of value, and the temporal stability of values, as well as achieve better integration of intrinsic values.

Kronenberg and Andersson (2019) investigate prospects for integrating social, monetary and ecological valuation methods. These authors propose that one can never integrate all value dimensions and values, but should strive to achieve as comprehensive a view as possible. They illustrate these points through a framework that guides decisions on integration potential. The framework reflects two dimensions of logical and axiological commensurability of values, as well as technical compatibility of valuation methods. Using this framework, the authors analyse the integration potential of social, ecological and monetary value indicators in terms of full integration (where there is full commensurability and compatibility) or combination (where there is some compatibility and commensurability). Where values are entirely incommensurable or incompatible, parallel use of the different valuation methods may still provide a more comprehensive picture than using a single category of value indicators alone. As this may occur in many cases, we need to develop skills/capacities for working across different dimensions of values.

A selection of papers looks at ways of forming shared social values. Ravenscroft (2019) point out that more normative views on economics, involving individuals working together to form values with respect to issues (i.e., normative value formation), are much less frequently discussed in debates around social values within that discipline than descriptive ones, which is problematic given that social valuation is an essentially normative rather than merely technical challenge. He proposes multiple principles of normative valuation formation; for example, the importance of social units as the scale of analysis, procedural justice in the deliberation of shared social values, instrumental outcomes being informed by deliberative valuation, and new dialectical approaches to decision-making.

Calcagni et al. (2019) in contrast consider non-monetary shared social values, exploring how multimedia content coconstructed by the users would expose the relational nature of social values assigned to cultural ecosystem services. These authors conduct a systematic review of studies of cultural ecosystem services using social media and find that recreation values were most frequently quantified, in addition to landscape aesthetics and cultural identity.

\section{What are processes for learning about, forming or changing social values?}

Social value change is considered in three different ways in this special feature. One paper considers value change through the framing of social learning, another explores the individual, group and socio-ecological mechanisms underpinning value change and two papers consider how institutions articulating religious values can form social values for sustainability.

Eriksson et al. (2019) examine social learning in terms of changes in understandings of social value that occurred among authors that contribute towards this special feature. In a survey that was administered before a deliberative workshop involving these experts, they found the contributors with backgrounds in diverse disciplines expressed multiple definitions of social values, many of which emphasized group- and societal level processes. In two post-test surveys administered after 2 weeks and then 3 months, they found individuals with less self-reported understanding of social values were more likely to change their definition during the course of deliberations.

Kendal and Raymond (2018) present a framework for understanding how values shift via changes to individuals, groups and social-ecological context. These authors identified a number of pathways through which people's values may change: (1) changes in the composition of the group due to immigration and emigration from the group over time; (2) changes within the individual due to factors such as maturation and socialization; and (3) changes in social-ecological context through environmental shocks (e.g., natural disasters) and stresses (e.g., increased temperatures caused by global climate change), and social-cultural changes.

Christie et al. (2019a) explore the potential impact and influence of religion, principally Catholic Social Teaching of the common good, on social values for sustainability. They outline the key features of Catholic Social Teaching and identify its relevance to management of the commons. 
This article argues that power laden ethical traditions and related social values of Catholic Social Teaching are essential for promoting transitions toward sustainability. Within such teachings is a perspective on 'integral ecology' that accounts for ecological concern, theology of care for creation, solidarity, human dignity, subsidiarity, and concern for the poor. However, there are some risks to considering this ethical perspective, including the potential for incompatibility and conflict in social values, which need to be navigated in environmental planning and management.

Ives and Kidwell (2019) suggest that religion has great potential to bring about positive change for sustainability because of the way it combines values with beliefs, practices and structures, and is a guiding influence in the lives of the vast majority of the global population. However, religion can conflict with goals for sustainability in some instances. They explored the intersection of religion and social values for sustainability, and the degree to which these concepts can be translated into environmental attitudes and behaviour to demonstrate that religion is a complex, multi-scalar and multi-dimensional institutional phenomenon. Analysis of social values with reference to religion therefore needs to take account of narratives, histories and practices at the individual community and formal institutional level.

\section{What are the associations between social values and behaviour or well-being?}

Brear and Mbonane (2019) investigate the relationships between social values and sustainability practices by drawing on Bourdieu's sociological theory of practice; a philosophical, capabilities-based definition of needs and a conceptualisation of values as lived and relational. They find that value and need fulfilment practices are often influenced by cultural values, but need fulfilment practices hold multiple layers of often contradictory meaning.

Raymond and Raymond (2019) compare and contrast understandings of social values and well-being across the positive psychology and environmental values literatures. These authors show how positive psychology provides a more nuanced picture of the relationship between social values and well-being outcomes through psychological processes (e.g., mindfulness) and needs (e.g., relatedness, autonomy, competence), and distinct pathways ('value activation' and 'healthy values').

van Riper et al. (2019) test how variation in behavioural patterns could be explained by cultural, communal and individual values tied to the ecological integrity of a national park in the United States. These authors bring empirical evidence to bear in a model that tested relationships that were theorized in previous research, and generate recommendations for managers on how best to communicate with protected area visitors in a way that aligns with underlying value orientations. Results from this study demonstrate that the dynamics of multi-level values are important for predicting environmental behaviour.

Fordham and Robinson (2019) investigate how social values drive corporate social responsibility (CSR) practice across a hierarchy of influence involving individuals, groups, communities, and broader society. They find that institutional behaviours related to sustainability are challenged when individuals within the workplace embed their ethical values into CSR. The multi-level framework investigated in this paper enables a comparative analysis of value formation across individual, group, community, and societal value providers, and the scope for examining different CSR practices.

Horcea-Milcu et al. (2019) differentiate four general perspectives of how and where values are important for transformation related to sustainability science of: surfacing implicit values, negotiating values, eliciting values, and transformation through values. These authors propose that a value-based perspective in sustainability transformations research can help move beyond general discussions implying values matter, raise researchers' awareness of their positionality when investigating values and reflect on the operationalization of values in different contexts.

\section{Cross-cutting themes that emerged in this special feature}

Important recurring themes emerge across theoretical traditions that were represented in this special feature. Each theme is introduced below and expanded upon in a detailed synthesis paper (Kenter et al. 2019).

\section{Values can be conceptualised across multiple dimensions, linked to lenses of worth}

This special feature highlights that social values can be conceptualised, measured and expressed in a plurality of ways. These diverse contributions are at risk of being overlooked in assessments that primarily focus on the content of values along a single dimension of discrimination, such as ecosystem assessments that focus on value justification (e.g., the content of instrumental, intrinsic and relational values). Kenter et al. (2019) synthesise the diversity of perspectives relating to the conceptualisation and assessment of social values for sustainability, as presented in this special feature (see Fig. 2 for overview). They identify three types of lenses: value, epistemic and procedural lenses, as well as present dimensions of values and valuation within them. Each of these dimensions can in turn be expressed as a question. The questions raised under each lens are intended to assist scholars identify, assess and compare different perspectives on social values for sustainability. The value lens of a social 
Fig. 2 Value, epistemic and procedural lenses for representing the diversity of perspectives relating to the conceptualisation and assessment of social values for sustainability (Kenter et al. 2019)

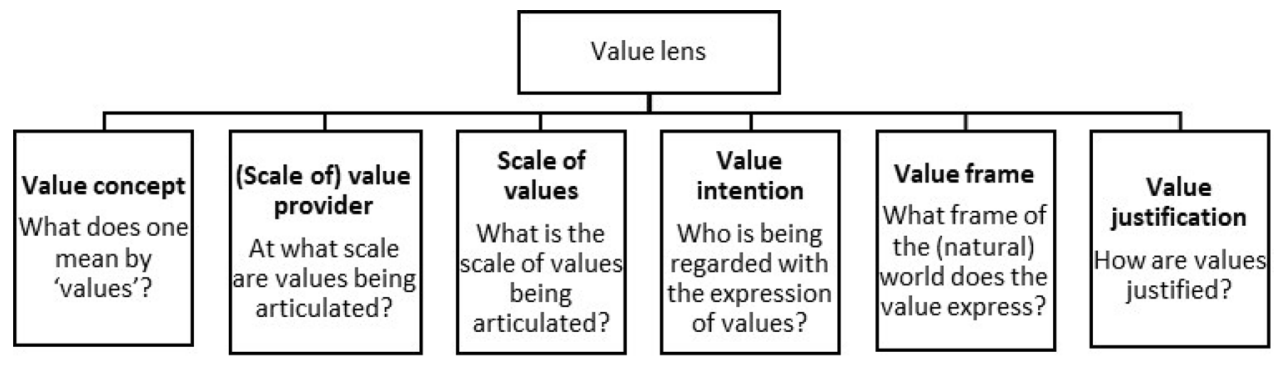

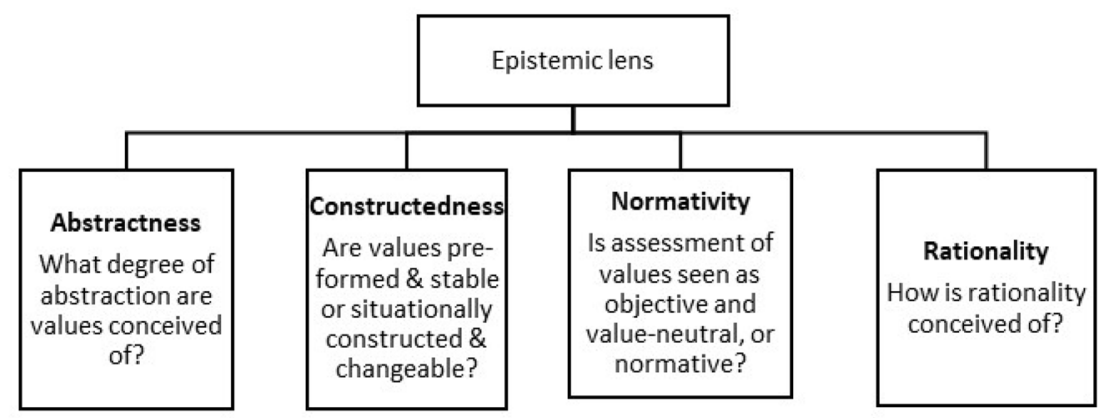

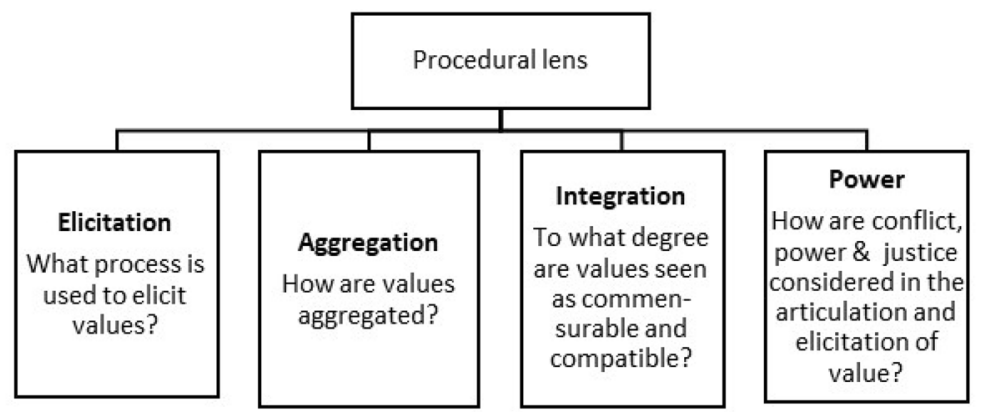

value tradition highlights how it conceives of the worth of something, and in what ways this is related to the social. This lens relates to questions about what concept, scale and intention of values is assumed. In turn, each value lens is perceived through meta-lenses. The authors describe metalenses as comprising specific theories and bodies of scientific or local and indigenous knowledge that articulate different perspectives on social valuation, including meta-values (values about values, for example, about how values should be aggregated; Kenter et al. 2016a). The difference between value lenses and meta-lenses highlights the importance of differentiating between the descriptive question of how people value (value lenses) and the normative question of how we should approach descriptions of such values, i.e. conduct valuation (meta-lenses) (Kenter et al. 2019; Stålhammar and Thorén 2019). Two types of meta-lenses are distinguished. Epistemic lenses describe the philosophical orientation of the researcher that guides their social value lens, including their view of the purpose of social valuation as descriptive, or normative and potentially transformative (also see Stålhammar and Thorén 2019; Horcea-Milcu et al. 2019).
Procedural lenses point to important processes that affect the way in which values are formed, elicited and shared (also see Ravenscroft 2019), aggregated or integrated (also see Kronenberg and Andersson 2019; O'Connor and Kenter 2019).

\section{Values are nested in different hierarchies}

Contributions in this special feature reveal that social values are nested in different hierarchies. Values can be nested within different value providers. Fordham and Robinson (2019) demonstrate that CSR issues varied depending on the scale of the value providers (e.g., individuals, group, community, society). Values formed at group and community scales are found to be particularly influential on individual decisions to address CSR issues, although in some instances, individuals were able to challenge existing institutional frameworks to promote CSR actions. Secondly, values can have different scales of intention in that individuals can express values at individual, group or cultural scales. van Riper et al. (2019) show through structural equation modelling that values can form and 
spread through individual and cultural contexts, which in-turn have an impact on the behavioural intentions of individuals and groups.

Complicating an assessment of value hierarchies, in some cultures, values are not typically discussed but demonstrated through different forms of action. The importance of practice is revealed in work on 'lived social values' (Brear and Mbonane 2019), and the values of Hawaiian communities (Gould et al. 2019). For example, 'kuleana' in Hawaiian communities relates to traditional management norms ascribed to people or families, and the rights and responsibilities associated with these which demonstrate these lived values in practice (Gould et al. 2019).

\section{Many values are not pre-formed, and require pathways of deliberation and/or intervention to be formed or activated}

It has for some time been acknowledged that environmental values, and more broadly values surrounding complex social issues, are frequently poorly formed (Spash and Hanley 1995). Recent agenda-setting conceptual and empirical work on social, shared and (socio)cultural values in ecological economics, biodiversity conservation and ecosystem service assessment have re-ignited this argument, highlighting value activation and formation through deliberative settings (e.g., Raymond et al. 2014; Ives and Kendal 2014; Kenter et al. 2015, 2016a, b; Irvine et al. 2016; Raymond and Kenter 2016). Here, the focus is on how values are activated or formed in social groups, with activation referring to values that lay dormant until triggered by a relevant context, and formation referring to a process whereby new values are constructed (Kenter et al. 2016c). Ravenscroft (2019) refers to this branch of work as 'normative economics' involving people meeting collectively to form and express a bespoke set of values that become shared. He argues for the balancing of descriptive and normative economics whereby instrumental outcomes are informed by deliberative valuation.

Positive psychology provides alternative theories on value activation. Rather than values being activated and shared through deliberation, they can also be activated through action, otherwise referred to as the 'value activation pathway'. Here value activation refers to the "processes which enable individuals to demonstrate behaviour that is consistent with their self-related attitudes, traits or norms" (Raymond and Raymond 2019, p. 8). Raymond and Raymond propose that mindfulness interventions could be applied as a method to clarify and activate values within a nature exposure context at the level of the individual. What the two approaches have in common is that both can be used to harness values as 'levers' (Everard et al. 2016) for transformation (Horcea-Milcu et al. 2019; Kenter et al. 2019).

\section{Value integration may not always be possible or necessary}

Recent contributions point to a plethora of methods for integrating socio-cultural values with other value dimensions (e.g., Scholte et al. 2015; Arias-Arévalo et al. 2018). Given the different perspectives on social values presented here, one needs to question whether empirical approaches to value integration are always possible, necessary or desirable. In many papers in this special feature, values from different lenses are narrated as opposed to empirically integrated (Gould et al. 2019; Ives and Kidwell 2019; O'Connor and Kenter 2019). Christie et al. (2019b) demonstrate how values could be elicited in parallel by drawing on the multiple evidence-based approach adopted by IPBES, without going into the details of value conflicts within and across theoretical traditions, and pointing out that IPBES has thus far lacked sufficient knowledge of processes for reconciling plural values and addressing value conflicts. Integration and aggregation of values is particularly complex when dealing with different theoretical traditions, because not just conflicting values but also potentially incompatible value lenses and meta-lenses need reconciliation, including diverging perspectives around value integration and aggregation itself. Kenter et al. (2019) point out a wide range of such tensions between different lenses, in relation to different social value dimensions. Kronenberg and Andersson (2019) highlight instances where values are commensurable, incommensurable but compatible and vice versa, and neither commensurable nor compatible requiring parallel use rather than integration. They imply that value pluralism may be an outcome itself, and important for navigating trade-offs and conflicts. In future research, there is an urgent need to develop processes for identifying and managing such conflicts in a professional manner, for example through 'practical judgement' (Martínez-Alier et al. 1998) and new democratic spaces (Kenter 2016a). Lessons may be drawn here also from indigenous practices of conflict resolution (Gould et al. 2019).

\section{Social values may change through different processes or pathways of intervention}

This special feature does not aim to settle the debate on the extent, speed and mechanism by which social values can change (Raymond and Kenter 2016; Manfredo et al. 2017; Ives and Fischer 2017). Rather, we identify different perspectives on how values could be harnessed for sustainability transformations (Horcea-Milcu et al. 2019), and the mechanisms through which values may change (Kendal and Raymond 2018; Raymond and Raymond 2019; van Riper et al. 2019). Papers identify different processes or pathways of change, including healthy values pathways where the 
emphasis is on aligning actions with intrinsic as opposed to an extrinsic value orientation and value activation pathways where the emphasis is on aligning actions with specific character strengths and virtues (Raymond and Raymond 2019). Also, there are pathways of value change associated with deliberative valuation (Ravenscroft 2019; O'Connor and Kenter 2019), in addition to processes associated with changes in group composition (e.g., immigration, emigration), maturation (e.g., ageing and socialization) and socioecological context (e.g., sudden changes to physical context wrought by climate change) (Kendal and Raymond 2018).

\section{Power matters in the formation and assessment of social values}

Three papers in this special feature highlight that power matters in the formation and assessment of social values. Brear and Mbonane (2019) demonstrate that practices from which people do not gain economically or materially can nonetheless be self-interested attempts to accumulate capital/power. Power in this context is conceived as gaining access to resources to support self-interests. Also, individuals adopt different roles depending on their situational needs. For example, in some cases, individuals strategically assign apparently altruistic values to objects in order to mask the self-interest of their daily actions. O'Connor and Kenter (2019) point to the potential of greening deliberative democracy, where rationality is conceived of as evoked by a noncoercive process of communication involving citizens, stakeholders and policy makers. They argue that, to ensure the procedural justice of valuation, the interests of non-humans need to be directly articulated, and such values demand more inclusive value taxonomies, such as encapsulated by the Life Framework. Massenberg (2019), in part, critiques economic theories relating issues of distribution, power and justice. He points to economic theories that could better account for externalities and power relations, and the environmental and societal effects caused by production and distribution.

\section{Future directions: navigating the plurality in social values for sustainability}

An important question of "how does one manage for the plurality in social values for sustainability?" naturally emerges from the main findings of this special feature. Consistent with post-normal science, we propose that there is not one optimal solution to the identification, integration and management of social values for sustainability because multiple perspectives on social values exist, with each perspective guided by different theoretical traditions and lenses of worth. In the title of this editorial, we use the term 'navigating' the plurality in social values for a special reason. The Oxford
Dictionary (2018) defines navigation as the "the process or activity of accurately ascertaining one's position and planning and following a route" Accordingly, we propose that after identifying the context to valuation, one's position on social values for sustainability needs to be clarified before proceeding to the analysis and application of a stance that there are multiple values of nature. This may sound obvious, but we have observed that much of the literature that forms the basis of this special feature overlooks the perspective of the researcher, or only deals with it lightly.

The process of ascertaining one's positions is often nonlinear and has multiple feedbacks (Fig. 3). We propose that the management problem and the ways in which social values have been applied to the problem in the past (i.e., the context) informs the theoretical starting point one chooses on social values for sustainability (perspective) (Fig. 3a). However, in some approaches, such as participatory action research, the perspective taken by the researcher can also influence the context and vice versa (Fig. 3b). Having identified one's perspective, researchers are then encouraged to consider from which theoretical starting point(s) they plan to explore or examine social values [e.g., normative economics (Ravenscroft 2019), (Fig. 3c)] and to be reflexive of the lenses of worth they plan to use with reference to the theoretical tradition (Fig. 3d), including which value, epistemic and procedural lenses (Fig. 2). Integrating or comparing social values from lenses of different traditions is likely to result in multiple tensions (for an overview of key tensions, see Kenter et al. 2019) (Fig. 3e). Also, each lens may lead to different processes of value articulation and application, and implications for sustainability planning (Fig. 3f).

One of the major gaps in social values for sustainability research relates to how to manage tensions, and the associated conflicts and unequal power relations that surface during the analysis and application of social values for sustainability that are informed by different perspectives and lenses of worth (Fig. 3g). Large-scale assessments like IPBES and IPCC have been increasingly effective at recognising plurality of knowledge, but have often overlooked contrasting rationalities, ontological claims and knowledge forms and how to manage conceptual or social conflicts among those who have different perspectives (Löfmarck and Lidskog 2017; Ford et al. 2016; Christie et al. 2019b; Hulme 2011). Power relations can be considered by exploring the power relations which underpin the governance and institutions that determine access to and control over natural resources, assessing labour relations and recognising the historical factors that shape power relations and environmental change (Berbés-Blázquez et al. 2016), as well as the power associated with social status and prevailing societal discourses, such as that of perpetual economic growth (Orchard-Webb et al. 2016). The knowledge co-production literature suggests power relations can be managed by building of confidence 


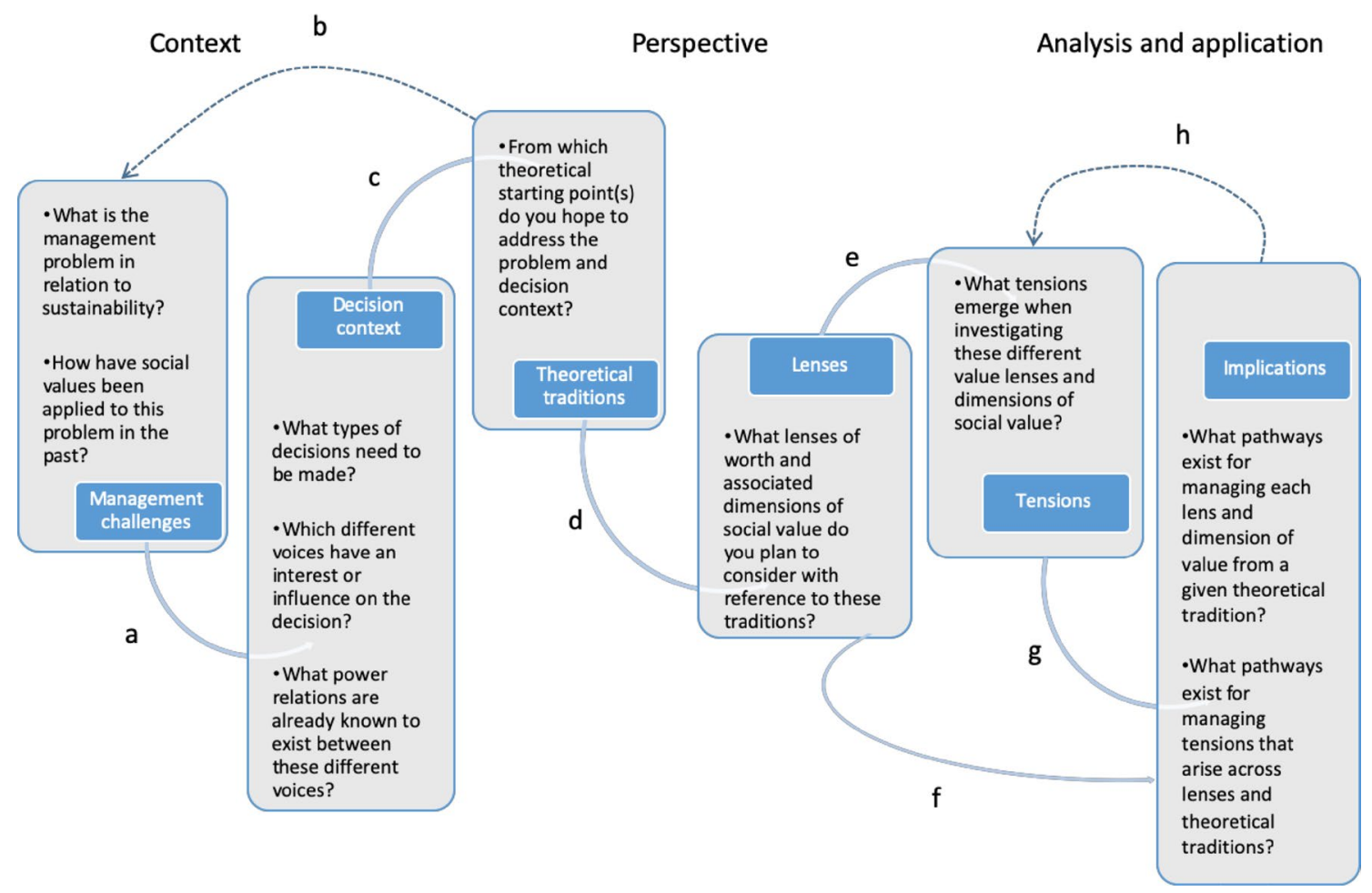

Fig. 3 Navigating the plurality of social values for sustainability, including the potential for feedbacks between context, positions, analysis and application

across knowledge systems through tasks like mobilisation (surfacing knowledge), translating (building mutual comprehension), negotiating (joint assessment of convergence and divergence and management of conflicts), synthesis (shaping a broadly accepted common knowledge) and applications (supporting knowledge useable for decision-making) (Tengö et al. 2017).

We recommend that a deeper understanding of partnership attributes, communication behaviour, and conflict resolution techniques (see Mohr and Spekman 1994; Humphreys 2005 for overview of principles) are needed in future work on social values for sustainability to surface and manage conflicts associated with tensions presented here. One also needs to recognise the potential for power relations and conflicts stemming from outside forces, including decisionmakers responsible for using the results of any given valuation (Shapira et al. 2019) (path (h), Fig. 3).

\section{Conclusion}

This special feature provides a reference point for scholars seeking to widen the theoretical traditions of social values included in sustainability science and practice. We consider different traditions across the four questions of: (1) How do we conceptualise social values? (2) How do we integrate or establish shared social values? (3) What are processes for learning about, forming or changing social values? and (4) What are the associations between social values and behaviour or well-being? We argue that a pluralistic and critical perspective is required on social values for sustainability, recognising that different lenses of worthiness exist, and that within and across disciplines there are different theoretical starting points. Rather than blindly integrating social values to inform sustainability outcomes, we encourage scholars to 'navigate the tensions' in social values across theoretical perspectives in order to obtain a more nuanced perspective. Navigation necessarily involves understanding one's current position and direction of travel, as well the different pathways or possibilities which stem from tensions that are identified along the journey. With reference to this special feature, it means clearly situating management challenges and decision contexts in which social values will be investigated, the different theoretical traditions on social values relevant to this context and the different lenses and meta-lenses of value within each tradition. By comparing lenses, one can then better understand the tensions associated with conceptualising, assessing or integrating social values for sustainability, and then develop pathways for managing them.

Acknowledgements We would like to thank the Valuing Nature Programme for funding a paper-writing workshop associated with this 
special feature (funded by the UK Natural Environment Research Council (NERC) under grant reference NE/M005410/1). Also, we would like to thank all special feature authors and reviewers for the timely and insightful contributions to this body of work.

\section{References}

Arias-Arévalo P, Martín-López B, Gómez-Baggethun E (2017) Exploring intrinsic, instrumental, and relational values for sustainable management of social-ecological systems. Ecol Soc. https://doi. org/10.5751/es-09812-220443

Arias-Arévalo P, Gómez-Baggethun E, Martín-López B, Pérez-Rincón M (2018) Widening the evaluative space for ecosystem services: a taxonomy of plural values and valuation methods. Environ Values 27:29-53. https://doi.org/10.3197/096327118X15144698637513

Arrow K, Solow R, Portney P et al (1993) Report of the NOAA Panel on Contingent Valuation. Fed Reg 58:4602-4614

Batavia C, Nelson MP (2017) For goodness sake! what is intrinsic value and why should we care? Biol Conserv 209:366-376. https ://doi.org/10.1016/j.biocon.2017.03.003

Berbés-Blázquez M, González JA, Pascual U (2016) Towards an ecosystem services approach that addresses social power relations. Curr Opin Environ Sustain 19:134-143. https://doi.org/10.1016/j. cosust.2016.02.003

Brear MR, Mbonane BM (2019) Social values, needs, and sustainable water-energy-food resource utilisation practices: a rural Swazi case study. Sustain Sci. https://doi.org/10.1007/s11625-019-00717 $-5$

Bryan BA, Raymond CM, Crossman ND, Macdonald DH (2010) Targeting the management of ecosystem services based on social values: where, what, and how? Landsc Urban Plan 97:111-122. https://doi.org/10.1016/j.landurbplan.2010.05.002

Calcagni F, Maia A, Connolly J, Langemeyer J (2019) Digital coconstruction of values for sustainability: exploring the potential of social media data in revealing relational values and informing sustainability science. Sustain Sci. https://doi.org/10.1007/s1162 5-019-00672-1

Callicott JB (1992) Rolston on intrinsic value. Environ Ethics 14:129143. https://doi.org/10.5840/enviroethics199214229

Carson R, Flores N, Meade N (2001) Contingent valuation: controversies and evidence. Environ Resour Econ 19:1730219

Chan KMA, Balvanera P, Benessaiah K et al (2016) Opinion: why protect nature? rethinking values and the environment. Proc Natl Acad Sci USA 113:1462-1465. https://doi.org/10.1073/ pnas. 1525002113

Chan KM, Gould RK, Pascual U (2018) Editorial overview: relational values: what are they, and what's the fuss about? Curr Opin Environ Sustain 35:A1-A7. https://doi.org/10.1016/J.COSUS T.2018.11.003

Christie I, Gunton RM, Hejnowicz AP (2019a) Sustainability and the common good: catholic social teaching and "integral ecology" as contributions to a framework of social values for sustainability transitions. Sustain Sci. https://doi.org/10.1007/s11625-01900691-y

Christie M, Martin-Lopez B, Church A et al (2019b) Understanding the diversity of values of "Nature's contributions to people": insights from the IPBES Assessment of Europe and Central Asia. Sustain Sci. https://doi.org/10.1007/s11625-019-00716-6

Cohen-Shacham E, Walters G, Janzen C, Maginnis S (eds) (2016) Nature-based solutions to address global societal challenges. IUCN, Gland, Switzerland, xiii + 97pp

Davidson MD (2013) On the relation between ecosystem services, intrinsic value, existence value and economic valuation. Ecol Econ 95:171-177. https://doi.org/10.1016/j.ecolecon.2013.09.002 de Groot RS, Wilson MA, Boumans RMJ (2002) A typology for the classification, description and valuation of ecosystem functions, goods and services. Ecol Econ 41:393-408. https://doi. org/10.1016/S0921-8009(02)00089-7

Díaz S, Pascual U, Stenseke M et al (2018) Assessing nature's contributions to people. Science 359:270-272. https://doi.org/10.1126/ science.aap 8826

Díaz S, Settele J, Brondízio E et al (2019) IPBES, Summary for policymakers of the global assessment report on biodiversity and ecosystem services of the intergovernmental science-policy platform on biodiversity and ecosystem services. Advance unedited version. Plenary of the intergovernmental science-policy platform on biodiversity and ecosystem services, seventh session, Paris, 29 April-4 May 2019. https://www.ipbes.net/system/tdf/ipbes 7_10_add-1-_advance_0.pdf?file $=1 \&$ type $=$ node $\& i d=35245$

Dietsch AM, Manfredo MJ, Sullivan L et al (2019) A multilevel, systems view of values can inform a move towards human-wildlife coexistence. Human-wildlife interactions. Cambridge University Press, Cambridge, pp 20-44

Eriksson M, van Riper C, Leitschuh B et al (2019) Social learning as a link between the individual and the collective: evaluating the deliberation of social values. Sustain Sci. https://doi.org/10.1007/ s11625-019-00725-5

European Commission (2015) Towards an EU research and innovation policy agenda for nature-based solutions \& re-naturing cities. Final report of the Horizon 2020 expert group on "Naturebased solutions and re-naturing cities". European Commission Directorate-General for Research and Innovation, Brussels. https ://ec.europa.eu/programmes/horizon2020/en/news/towards-euresearch-and-innovation-policy-agenda-nature-based-solutionsre-naturing-cities

Evans NM (2019) Ecosystem services: on idealization and understanding complexity. Ecol Econ 156:427-430. https://doi. org/10.1016/J.ECOLECON.2018.10.014

Everard M, Reed MS, Kenter JO (2016) The ripple effect: institutionalising pro-environmental values to shift societal norms and behaviours. Ecosyst Serv. https://doi.org/10.1016/j.ecoser.2016.08.001

Ford JD, Cameron L, Rubis J et al (2016) Including indigenous knowledge and experience in IPCC assessment reports. Nat Clim Chang 6:349-353. https://doi.org/10.1038/nclimate2954

Fordham A, Robinson G (2019) Identifying the social values driving corporate social responsibility. Sustain Sci. https://doi. org/10.1007/s11625-019-00720-w

Gómez-Baggethun E, Martín-López M, Barton D et al (2014) EU FP7 OpenNESS Project Deliverable 4.1, State-of-the-art report on integrated valuation of ecosystem services. Brussels. http:// www.openness-project.eu/sites/default/files/Deliverable\%20 4\%201_Integrated-Valuation-Of-Ecosystem-Services.pdf

Gould R, Pai M, Muraca B, Chan K (2019) He 'ike 'ana ia i ka pono (It is a recognizing of the right thing): how one indigenous worldview informs relational values and social values. Sustain Sci. https:// doi.org/10.1007/s11625-019-00721-9

Harrison PA, Dunford R, Barton DN et al (2018) Selecting methods for ecosystem service assessment: a decision tree approach. Ecosyst Serv 29:481-498. https://doi.org/10.1016/J.ECOSER.2017.09.016

Himes A, Muraca B (2018) Relational values: the key to pluralistic valuation of ecosystem services. Curr Opin Environ Sustain 35:1-7. https://doi.org/10.1016/j.cosust.2018.09.005

Horcea-Milcu A, Abson D, Apetrei C et al (2019) Values in transformational sustainability science: four perspectives for change. Sustain Sci. https://doi.org/10.1007/s11625-019-00656-1

Hulme M (2011) Meet the humanities. Nat Clim Change 1:177-179. https://doi.org/10.1038/nclimate1150

Humphreys M (2005) Natural resources, conflict, and conflict resolution. J Conflict Resolut 49:508-537. https://doi.org/10.1177/00220 02705277545 
IPBES (2019) Global assessment report on biodiversity and ecosystem services of the Intergovernmental Science-Policy Platform on Biodiversity and Ecosystem Services. E. S. Brondizio, J. Settele, S. Díaz, and H. T. Ngo (editors). IPBES Secretariat, Bonn, Germany

Irvine KN, O'Brien L, Ravenscroft N et al (2016) Ecosystem services and the idea of shared values. Ecosyst Serv 21:184-193. https:// doi.org/10.1016/j.ecoser.2016.07.001

Ives CD, Fischer J (2017) The self-sabotage of conservation: reply to Manfredo et al. Conserv Biol 31:1483-1485. https://doi. org/10.1111/cobi.13025

Ives CD, Kendal D (2014) The role of social values in the management of ecological systems. J Environ Manage 144C:67-72. https://doi. org/10.1016/j.jenvman.2014.05.013

Ives CD, Kidwell J (2019) Religion and social values for sustainability. Sustain Sci. https://doi.org/10.1007/s11625-019-00657-0

Jacobs S, Dendoncker N, Martín-López B et al (2016) A new valuation school: integrating diverse values of nature in resource and land use decisions. Ecosyst Serv 22:213-220. https://doi.org/10.1016/j. ecoser.2016.11.007

Jacobs S, Martín-López B, Barton DN et al (2018) The means determine the end - Pursuing integrated valuation in practice. Ecosyst Serv 29:515-528. https://doi.org/10.1016/J.ECOSER.2017.07.011

Kendal D, Raymond C (2018) Understanding pathways to shifting values over time in the context of social-ecological systems. Sustain Sci. https://doi.org/10.1007/s11625-018-0648-0

Kenter JO (2016a) Editorial: shared, plural and cultural values. Ecosyst Serv 21:175-183. https://doi.org/10.1016/j.ecoser.2016.10.010

Kenter JO (2016b) Integrating deliberative monetary valuation, systems modelling and participatory mapping to assess shared values of ecosystem services. Ecosyst Serv 21:291-307. https://doi. org/10.1016/j.ecoser.2016.06.010

Kenter JO (2018) IPBES: don't throw out the baby whilst keeping the bathwater; put people's values central, not nature's contributions. Ecosyst Serv 33:40-43. https://doi.org/10.1016/J.ECOSE R.2018.08.002

Kenter JO, Hyde T, Christie M, Fazey I (2011) The importance of deliberation in valuing ecosystem services in developing countries-evidence from the Solomon Islands. Glob Environ Chang 21:505-521. https://doi.org/10.1016/j.gloenvcha.2011.01.001

Kenter JO, O'Brien L, Hockley N et al (2015) What are shared and social values of ecosystems? Ecol Econ 111:86-99. https://doi. org/10.1016/j.ecolecon.2015.01.006

Kenter JO, Bryce R, Christie M et al (2016a) Shared values and deliberative valuation: future directions. Ecosyst Serv. https://doi. org/10.1016/j.ecoser.2016.10.006

Kenter JO, Jobstvogt N, Watson V et al (2016b) The impact of information, value-deliberation and group-based decision-making on values for ecosystem services: integrating deliberative monetary valuation and storytelling. Ecosyst Serv 21:270-290. https://doi. org/10.1016/j.ecoser.2016.06.006

Kenter JO, Reed MS, Fazey I (2016c) The deliberative value formation model. Ecosyst Serv 21:194-207. https://doi.org/10.1016/j. ecoser.2016.09.015

Kenter J, Raymond CM, van Riper CJ et al (2019) Loving the mess: Navigating diversity and conflict in social values for sustainability. Sustain Sci. https://doi.org/10.1007/s11625-019-00726-4

Klain SC, Satterfield TA, Chan KMA (2014) What matters and why? Ecosystem services and their bundled qualities. Ecol Econ 107:310-320. https://doi.org/10.1016/J.ECOLECON.2014.09.003

Kronenberg J, Andersson E (2019) Integrating social values with other value dimensions: parallel use vs. combination vs. full integration. Sustain Sci. https://doi.org/10.1007/s11625-019-00688-7

Löfmarck E, Lidskog R (2017) Bumping against the boundary: IPBES and the knowledge divide. Environ Sci Policy 69:22-28. https:// doi.org/10.1016/j.envsci.2016.12.008
Manfredo MJ, Bruskotter JT, Teel TL et al (2017) Why social values cannot be changed for the sake of conservation. Conserv Biol. https://doi.org/10.1111/cobi.12855

Martínez-Alier J, Munda G, O’Neill J (1998) Weak comparability of values as a foundation for ecological economics. Ecol Econ 26:277-286. https://doi.org/10.1016/S0921-8009(97)00120-1

Massenberg JR (2019) Social values and sustainability: a retrospective view on the contribution of economics. Sustain Sci. https ://doi.org/10.1007/s11625-019-00693-w

Mohr J, Spekman R (1994) Characteristics of partnership success: partnership attributes, communication behavior, and conflict resolution techniques. Strateg Manag J 15:135-152. https:// doi.org/10.1002/smj.4250150205

Muraca B (2011) The map of moral significance: a new axiological matrix for environmental ethics. Environ Values 20:375-396

Muraca B (2016) Relational values. Balk J Philos 8:19-38. https:// doi.org/10.5840/bjp2016813

O'Connor S, Kenter J (2019) Making intrinsic values work; integrating intrinsic values of the more-than-human world through the life framework of values. Sustain Sci. https://doi.org/10.1007/ s11625-019-00715-7

O'Neill J (1992) The varieties of intrinsic value. Monist 75:119-133

O'Neill J, Holland A, Light A (2008) Environmental values. Routledge, London and New York

Orchard-Webb J, Kenter JO, Bryce R, Church A (2016) Deliberative democratic monetary valuation to implement the ecosystem approach. Ecosyst Serv 21:308-318. https://doi.org/10.1016/j. ecoser.2016.09.005

Oxford Dictionary (2018) Definition of navigation in English. https ://en.oxforddictionaries.com/definition/navigation. Accessed 24 Mar 2019

Pascual U, Balvanera P, Díaz S et al (2017) Valuing nature's contributions to people: the IPBES approach. Curr Opin Environ Sustain. https://doi.org/10.1016/j.cosust.2016.12.006

Piccolo JJ (2017) Intrinsic values in nature: objective good or simply half of an unhelpful dichotomy? J Nat Conserv 37:8-11. https ://doi.org/10.1016/j.jnc.2017.02.007

Poteete AR, Janssen M, Ostrom E (2010) Working together: collective action, the commons, and multiple methods in practice. Princeton University Press, Princeton

Ravenscroft N (2019) A new normative economics for the formation of shared social values. Sustain Sci. https://doi.org/10.1007/ s11625-018-0652-4

Rawluk A, Ford R, Anderson N, Williams K (2018a) Exploring multiple dimensions of values and valuing: a conceptual framework for mapping and translating values for social-ecological research and practice. Sustain Sci. https://doi.org/10.1007/s1162 5-018-0639-1

Rawluk A, Ford RM, Williams KJH (2018b) Value-based scenario planning: exploring multifaceted values in natural disaster planning and management. Ecol Soc 23:art2. https://doi.org/10.5751/ es-10447-230402

Raymond CM, Kenter JO (2016) Transcendental values and the valuation and management of ecosystem services. Ecosyst Serv. https ://doi.org/10.1016/j.ecoser.2016.07.018

Raymond I, Raymond C (2019) Positive psychology perspectives on social values and their application to intentionally delivered sustainability interventions. Sustain Sci. https://doi.org/10.1007/ s11625-019-00705-9

Raymond CM, Bryan BA, MacDonald DH et al (2009) Mapping community values for natural capital and ecosystem services. Ecol Econ 68:1301-1315. https://doi.org/10.1016/j.ecole con.2008.12.006

Raymond CM, Brown G, Robinson GM (2011) The influence of place attachment, and moral and normative concerns on the conservation of native vegetation: a test of two behavioural models. $\mathbf{J}$ 
Environ Psychol 31:323-335. https://doi.org/10.1016/j.jenvp .2011.08.006

Raymond CM, Singh GG, Benessaiah K et al (2013) Ecosystem services and beyond: using multiple metaphors to understand humanenvironment relationships. Bioscience. https://doi.org/10.1525/ bio.2013.63.7.7

Raymond CM, Kenter J, Turner N, Alexander K (2014) Comparing instrumental and deliberative paradigms underpinning the assessment of social values for cultural ecosystem services. Ecol Econ 107:145-156

Raymond CM, Frantzeskaki N, Kabisch N et al (2017) A framework for assessing and implementing the co-benefits of nature-based solutions in urban areas. Environ Sci Policy. https://doi.org/10.1016/j. envsci.2017.07.008

Raymond CM, Kenter J, Kendal D et al (2018) Call for papers for "Theoretical traditions in social values for sustainability". Sustain Sci. https://doi.org/10.1007/s11625-018-0537-6

Rolston H (1988) Environmental ethics: duties to and values in the natural world. Temple University Press, Philadelphia

Scholte SSK, van Teeffelen AJA, Verburg PH (2015) Integrating socio-cultural perspectives into ecosystem service valuation: a review of concepts and methods. Ecol Econ 114:67-78. https:// doi.org/10.1016/j.ecolecon.2015.03.007

Schwartz SH (1994) Are there universal aspects in the structure and contents of human values? J Soc Issues 50:19-45

Shapira N, Housh M, Broitman D (2019) Decision-makers matter: an operational model for environmental-economic conflict resolution. Environ Sci Policy 98:77-87. https://doi.org/10.1016/j.envsc i. 2019.05 .010

Spash CL, Hanley N (1995) Preferences, information and biodiversity preservation. Ecol Econ 12:191-208. https://doi. org/10.1016/0921-8009(94)00056-2
Stålhammar S, Thorén H (2019) Three perspectives on relational values of nature. Sustain Sci. https://doi.org/10.1007/s11625-019-00718 $-4$

Teel TL, Manfredo MJ, Stinchfield HM (2007) The need and theoretical basis for exploring wildlife value orientations cross-culturally. Hum Dimens Wildl 12:297-305. https://doi.org/10.1080/10871 200701555857

Tengö M, Hill R, Malmer P et al (2017) Weaving knowledge systems in IPBES, CBD and beyond-lessons learned for sustainability. Curr Opin Environ Sustain 26-27:17-25. https://doi.org/10.1016/j. cosust.2016.12.005

Tinch R, Beaumont N, Sunderland T et al (2019) Economic valuation of ecosystem goods and services: a review for decision makers. J Environ Econ Policy 92:1-20. https://doi.org/10.1080/21606 544.2019.1623083

van Riper CJ, Landon AC, Kidd S et al (2017) Incorporating sociocultural phenomena into ecosystem-service valuation: the importance of critical pluralism. Bioscience. https://doi.org/10.1093/biosci/ biw170

van Riper CJ, Thiel A, Penker M et al (2018) Incorporating multilevel values into the social-ecological systems framework. Ecol Soc 23:art25. https://doi.org/10.5751/es-10047-230325

van Riper C, Winkler-Schor S, Stamberger L et al (2019) Integrating multi-scale values and pro-environmental behavior in a protected area. Sustain Sci. https://doi.org/10.1007/s11625-019-00677-w

Publisher's Note Springer Nature remains neutral with regard to jurisdictional claims in published maps and institutional affiliations. 